\title{
Research of Focal Mechanism and Focal Depth of Qilian, Qinghai $M_{\mathrm{s}}$ 5.2 Earthquake
}

\author{
Yongguo $\mathrm{GAO}^{1}$, Xinxin $\mathrm{Yin}^{1, *}$ \\ ${ }^{1}$ Earthquake Administration of Gansu Province, Lanzhou, 730000, China
}

\begin{abstract}
This paper selects the waveform records of 16 broadband digital seismic stations in the regional seismic network of Gansu province, Qinghai province, and Sichuan province involved inversion, use CAP focal mechanism solution method to calculate the Ms 5.2 earthquake which occurred in Qilian County, Qinghai Province, November 23, 2015. Obtained the focal mechanism solution of this earthquake is a strike-slip fault with thrust property. The inversion results show the optimal double couple solution is nodal plane I: The strike is $112^{\circ}$, the dip, $51.7^{\circ}$; and the rake, $24.5^{\circ}$. Nodal plane II: The strike is $7^{\circ}$, the dip, $71^{\circ}$; and the rake, $139^{\circ}$. Earthquake moment magnitude is $M_{\mathrm{w}} 5.2$ and the optimal depth solution is $8 \mathrm{~km}$, which is consistent with the results of IGP-CEA. We calculate focal depth with the arrival time difference between sPn and Pn phases, the results is $6.6 \mathrm{~km}$, which agree with the CAP method results and verify the feasibility of this method.
\end{abstract}

\section{Background}

Focal depth is one of the most difficult parameters to accurately measure as a basic parameter of seismic space-time parameters. Accurate determination of focal depth is related to the correct understanding of a series of important issues such as focal process, fault structure, and stress field. For larger earthquakes, accurate determination of focal depth is an important reference factor for judging focal intensity. Because there are fewer seismic stations in the upper and lower directions, depth positioning is not as accurate as horizontal positioning and focal depth is a relatively difficult quantity to determine in earthquake location. The regional seismic network is usually based on a onedimensional velocity model, using $\mathrm{Pg}(\mathrm{Sg})$ and $\mathrm{Pn}(\mathrm{Sn})$ phases to locate earthquakes. Due to the Pn (Sn) spreading distance is far, the traveling time of the seismic phase is easily affected by lateral heterogeneity of medium. Seismic location based on $\mathrm{Pg}(\mathrm{Sg})$ phase can only obtain high precision focal depth when the number of near stations is sufficient and the station azimuth coverage is good. Under the circumstances of the seismic network relatively sparse, due to the lack of sufficient near station data, the accuracy of focal depth determined by conventional positioning methods is low. At present, the layout of most stations in China is relatively sparse, so the deep seismic phase method will have a better effect.

According to CENC, an Ms5.2 earthquake occurred in Qilian County, Haibei Tibetan Autonomous Prefecture, Qinghai Province $\left(37.65^{\circ} \mathrm{E}, 101.62^{\circ} \mathrm{N}\right)$ on 5:2:42, November 23, 2015 (GMT+8), with a focal depth of $10 \mathrm{~km}$. Earthquakes are felt in many places in Qinghai and Gansu, earthquakes have a greater effect on the Qilian County of Qinghai Province and Sunan County of Gansu Province. Earthquakes occurred in the Qilian fault zone and its styles mainly are large sinistral strike-slip faults.

\section{Regional tectonic background and aftershock distribution}

The Haiyuan fault imitates at the Hala lake in the Qilian Shan to the west, goes through the Menyuan county of Qinghai Province, Jingtai county of the Gansu Province and Haiyuan county of the Ningxia Hui autonomous region eastward, terminates at south of Zhongwei county at the most east, and merge into Liupan Shan uplift area. The east section of the Haiyuan fault is a boundary of Qilian and Alxa blocks, slips left-laterally with vertical motion locally. Strong earthquakes occurred in the north of the Lenglongling section in recent years. Because of the Tibet plateau expansion northward, the Qilian Shan has been shortened and uplifted and formed a long banded Range-Basin feature. There are many minor thrusts with weak horizontal slip in this area, such as Danghe Nanshan fault, Shule Nanshan fault, central Qilian Shan fault, Yemahe fault, north Qilian Shan fault, and Fodongmiao-Hongyazi fault. There are also many minor faults distribute along the Hexi corridor, including Yumen fault, Jiayuguan fault, Helishan fault, Jinta Nanshan fault, Yumu Shan fault, Dahuang Shan fault, Longshou Shan fault, Shandan-Minle blind fault, and Gulang thrust. Fig 1 shows that aftershocks distributes with the trending of SE-NW.

*Corresponding author: yxx@gsdzj.gov.cn 


$$
\mathrm{e}=\left\|\left(\frac{r}{r_{0}}\right)^{p}\right\| \cdot\|u-s\|
$$

In the formula (3), $\mathrm{r}$ is the epicentral distance, $\mathrm{r} 0$ is the selected reference epicentral distance, $P$ is an exponential factor being adopted considering the influence of geometric diffusion factor on the seismic waveform, it makes the moment magnitude of earthquakes comparatively reliable. In reference to previous research experience [4], in general, body wave inversion $\mathrm{P}=1.0$, surface wave inversion $\mathrm{P}=0.5$.

The method divides the broadband seismic records into Pnl and surface waves to inversion focal mechanism solution. The focal mechanism solution with the smallest global difference between synthetic seismogram and observed seismogram is searched in an appropriate time range, which enhances the weight of Pnl and has better constraints on seismic depth.

\subsection{Brief introduction to the CAP method}

The CAP method is a full waveform inversion method compared with the previous P-wave first motion, body wave inversion or surface wave inversion. It divides broadband seismic records into Pnl and surface waves for inversion and allows them to float relatively, gain the focal mechanism solution with the smallest global difference between synthetic seismogram and observed seismogram within the appropriate time range. The CAP method has the characteristics of fewer requirements for the number of stations involved in inversion, azimuth distribution does not need to be very uniform, inversion results are less dependent on the velocity model and the lateral in homogeneity of crustal structure. At present, some research results fully prove the validity and reliability of the CAP method in focal mechanism solution and seismic centroid depths research [1-3].

The main principle of the CAP method is: the theoretical synthetic displacement $s(t)$ of any doublecouple source can be expressed as formula (1).

$$
\mathrm{s}(t)=M_{0} \sum_{i=1}^{3} A_{i}\left(\theta-\varphi_{s}, \delta, \lambda\right) G_{i}(t)
$$

In the formula, $\mathrm{i}=1,2,3$ respectively corresponds to three basic fault types: vertical strike-slip, vertical dipslip, and $45^{\circ}$ dip-slip; $\mathrm{G}_{i}$ is Green function, $\mathrm{A}_{i}$ is ray coefficient, $\theta$ is station azimuth angle, $\mathrm{M}_{0}$ is scalar moment; $\varphi_{\mathrm{s}}, \delta, \lambda$ respectively represents the direction, dip and slip angle of the obtained focal mechanism solution.

In the process of inversion, the synthetic seismic displacement $\mathrm{s}(\mathrm{t})$ and observed seismic displacement $\mathrm{u}$ (t) are consistent is taken as the judge criterion, as shown in formula (2)

$$
u(t)=s(t)
$$

\subsection{Data processing and calculating results}

We select the waveform records of 16 broadband digital seismic stations in the regional seismic network of Gansu province, Qinghai province, and Sichuan province [5-6] involved inversion, the distribution of seismic stations is shown in Fig 3, maximum station field angle is $42.4^{\circ}$. The epicenter distance is in the range of $50 \mathrm{~km} \sim 600 \mathrm{~km}$, and the waveform records have a higher signal-to-noise ratio. The used seismograph types include BBVS-60, CMG-3ESPC, CTS-1, BBVS-120, etc. The observation frequency band is $60 \mathrm{~s} \sim 50 \mathrm{~Hz}$ or 120 $\mathrm{s} \sim 50 \mathrm{~Hz}$, sampling rates all are $100 \mathrm{~Hz}$. The digital seismic data with a high signal-to-noise ratio have laid a good foundation for this study. All data was processed by remove mean, eliminate the responses of instruments, normalization, and filtering. We select the CRUST 2.0 global velocity model table 1 as the velocity model. The final results (see table 2) agree with the IGP-CEA results.

Table 1. Velocity model.

\begin{tabular}{|c|c|c|c|}
\hline $\begin{array}{c}\text { Layer } \\
\text { number }\end{array}$ & $\begin{array}{c}\text { Thickness/ } \\
\mathbf{k m}\end{array}$ & $\mathbf{V p} / \mathbf{k m} \times \mathbf{s}-\mathbf{1}$ & $\mathbf{V s} / \mathbf{k m} \times \mathbf{s}-\mathbf{1}$ \\
\hline 1 & 0.5 & 2.5 & 1.2 \\
\hline 2 & 18 & 6.1 & 3.5 \\
\hline 3 & 16 & 6.3 & 3.6 \\
\hline 4 & 9.5 & 7.2 & 4 \\
\hline 5 & 0 & 8 & 4.6 \\
\hline
\end{tabular}

An error objective function can be defined to measure the difference between $\mathrm{s}$ and $\mathrm{u}$ : 


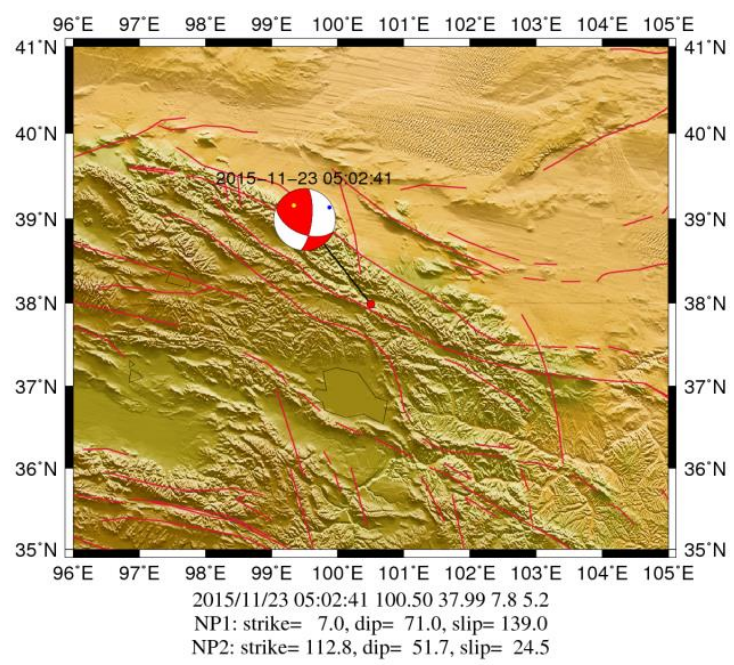

Fig. 2. The focal mechanism and relevant parameters.

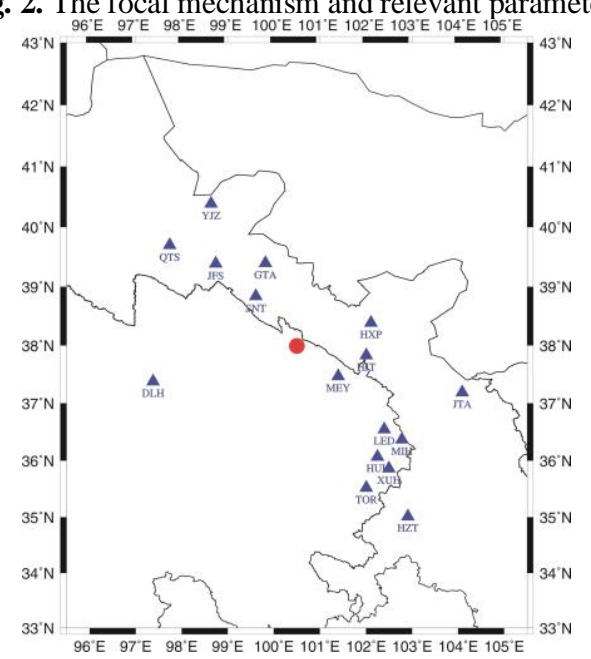

Fig. 3. The space distribution of 16 stations.

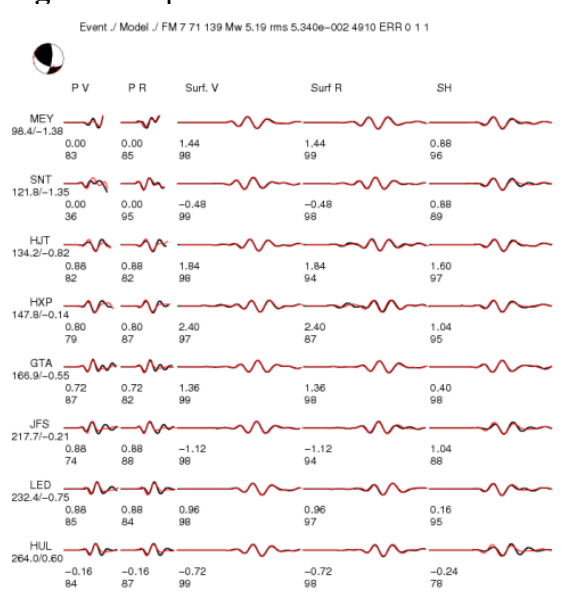

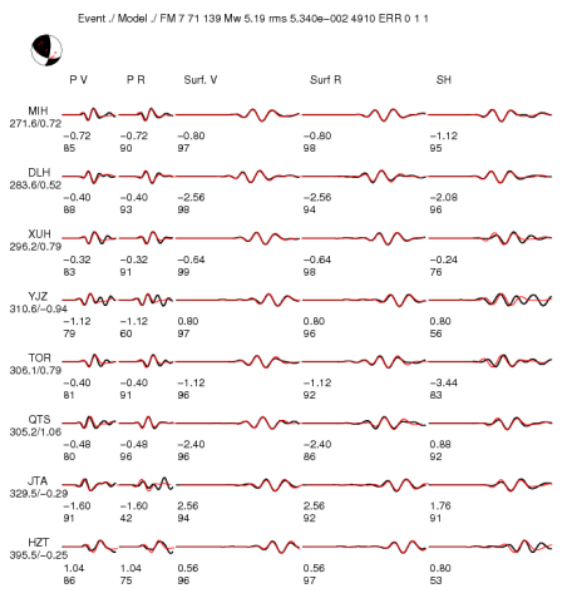

Fig. 4. Comparison of synthetic waveforms and observations in CAP method inversion in best focal depth.

Table 2. The contrast of each focal mechanism solutions.

\begin{tabular}{|c|c|c|c|c|c|c|c|}
\hline & Depth & \multicolumn{3}{|c|}{ Nodal Plane I $\left(^{\circ}\right)$} & \multicolumn{3}{c|}{ Nodal Plane II $\left(^{\circ}\right)$} \\
\hline & $($ Km) & Strike & Dip & Rake & Strike & Dip & Rake \\
\hline $\begin{array}{c}\text { This } \\
\text { Paper } \\
\text { Results }\end{array}$ & 8 & 112 & 51.7 & 24.5 & 7 & 71 & 139 \\
\hline $\begin{array}{c}\text { IGP- } \\
\text { CEA } \\
\text { Results }\end{array}$ & 9 & 110 & 54 & 15 & 11 & 78 & 143 \\
\hline
\end{tabular}

\section{The sPn seismic phase identification and depth calculation}

The sPn phase is a practical seismic phase for determining the focal depth of shallow earthquakes with short distance $(\Delta<1000 \mathrm{~km})$. Assuming that the source is not on the surface $(\mathrm{h} \neq 0)$ and to simplify the description, the crust is simplified as a double layer (Fig. 5).

When an earthquake occurs in the earth's crust, Swave rays incident on the earth's surface, reflect and convert to P-wave and then incident to Moho surface. When the incident angle is critical, the Pn wave is formed, since it is converted from $\mathrm{S}$ wave, it is denoted as sPn wave and its ray propagation path see Fig 5. Although the sPn wave keeps the dynamics characteristics of the shear wave and the amplitude and period are larger than that of the longitudinal wave, they appear in the seismic record in the form of a longitudinal wave. Therefore, the vertical direction is displayed, and the amplitude and period of the shear wave are larger than that of Pn. The sPn phase appears between Pn and $\mathrm{Pg}$. The paper using a double-layer seismic model theory calculates the arrival time difference between sPn and Pn. 


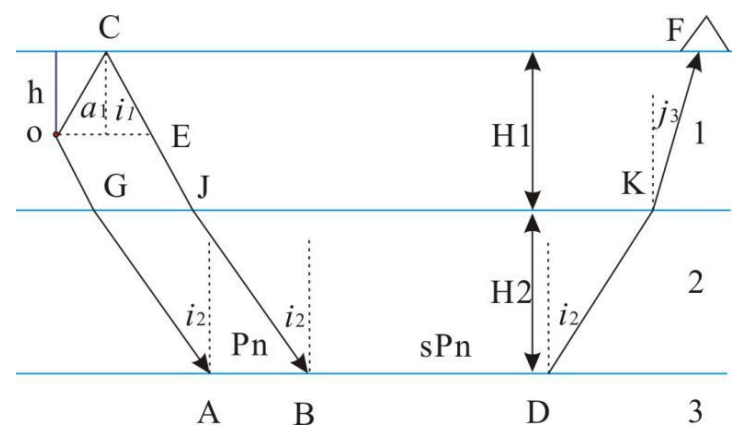

Fig. 5. Propagation path of sPn seismic phase from the doublelayered crustal model.

vs1 and v1 represent the propagation velocities of $S$ and $\mathrm{P}$ waves in the upper crust, respectively. v3 represents the propagation velocity of internal waves in the lower crust, that is, the propagation velocity of the Pn wave; the $h$ is focal depth. The arrival time difference of Pn wave can be deduced from the Snell law,

$$
\Delta \mathrm{t}=h\left(\frac{\sqrt{v_{3}^{2}-v_{s 1}^{2}}}{v_{3} \cdot v_{s 1}}+\frac{\sqrt{v_{3}^{2}-v_{1}^{2}}}{v_{3} \cdot v_{1}}\right)
$$

According to the crustal model of travel time difference of seismic wave in Gansu area [7-8], it can be deduced:

$\mathrm{v} 1=6.09 \mathrm{~km} / \mathrm{s}, \quad \mathrm{vs} 1=3.56 \mathrm{~km} / \mathrm{s}, \quad \mathrm{v} 3=8.17 \mathrm{~km} / \mathrm{s}, \quad$ then $\mathrm{K}=2.757$. That is the depth of the source in the upper crust: $\mathrm{h}=2.757 \Delta t$. The phase characteristic of $\mathrm{sPn}$ is that the arrival time difference independent of epicentral distance and only related to the focal depth. According to this property of the sPn phase, if moving the Pn phase of different epicentral distances to a line in the same time window, the sPn phase is also coming into a line. In this way, the sPn phase can be determined accurately and quickly, and then the focal depth can be determined. Fig 6 is Phase analysis from waveform. Waveform is processed by low-pass $1 \mathrm{~Hz}$ filtering. Station waveforms are arranged in order of epicentral distance is $\mathrm{ZHW}$, XSH, LQT, LTT, HYU, MXT, JNT, GYU, JYU. The transverse axis is coming into a line according to $\mathrm{Pn}$ phase, longitudinal axis distribution according to epicentral distance; it can be seen from the Fig 6 that the average the arrival time difference between $\mathrm{SPn}$ and $\mathrm{Pn}$ is about $2.4 \mathrm{~S}$. These parameters are substituted into the formula (1) obtained depth is $6.6 \mathrm{~km}$. Comparisons with CAP results of $8 \mathrm{~km}$, the error range is $1.4 \mathrm{~km}$, the gap between the two results is very small.

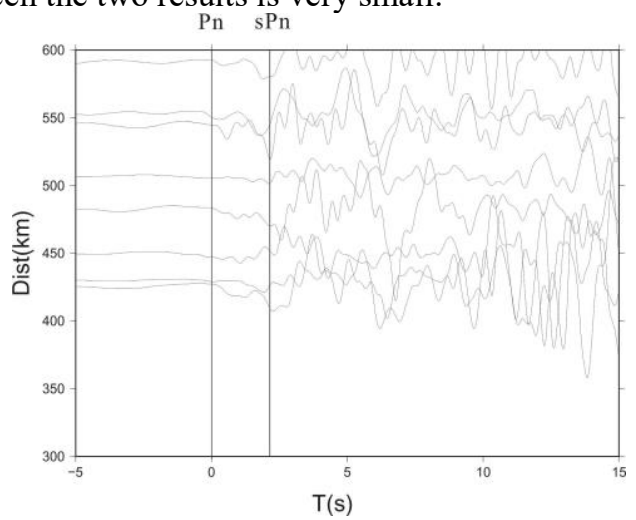

Fig. 6. Phase analysis from waveform.

\section{Conclusion and Discussion}

In this paper, we select 16 seismic stations waveform records to invert the $\mathrm{M}_{\mathrm{S}} 5.2$ Qilian earthquake by using CAP focal mechanism solution method. Combined with the tectonic background and aftershock distribution characteristics in Qilian area, determine the main axis parameters of the strike is $112^{\circ}$, the dip, $51.7^{\circ}$ and the rake, $24.5^{\circ}$, there was a left-lateral strike-slip fault with thrust property and optimal depth solution is $8 \mathrm{~km}$, the results agree with the IGP-CEA results. Based on the results of the focal mechanism and tectonic background of the Qilian region, it is concluded that the causative structure of this earthquake is a boundary fault zone between Qilian Mountain block and Alxa block in the eastern segment of Haiyuan fault. To compare the results of focal depths, this paper used the depth phase sPn method. Calculate the focal depth with the arrival time difference between $\mathrm{SPn}$ and $\mathrm{Pn}$ phases, the results of $6.6 \mathrm{~km}$ is consistent with the CAP method results of $8 \mathrm{~km}$. The focal depth of this earthquake is determined to be about $6-8 \mathrm{~km}$. The reliability of this method is verified by comparing it with the optimal depth solution of the CAP focal mechanism and other research institution's results.

The seismic waveform data used in this paper are from the Gansu Digital Seismic Network. All the charts in this paper are drawn by SAC, GMT and Matlab software.

\section{Acknowledgement}

Project funding: Special Fundamental Research Operational Fee of Institute of Earthquake Prediction, Seismological Bureau of China (2019 IESLZ07)

\section{References}

1. Zhao L S. Source estimation from broadband regional seismograms[J]. Bull. Seismol. Soc. Am. 1994, 84(1):91-104.

2. Zhu L, Helmberger D V. Advancement in source estimation techniques using broadband regional seismograms[J]. Bull. Seismol. Soc. Am. 1996, 86(5):1634-1641.

3. Feng L, Jiu Z Y, Ze W X, et al. Focal mechanism solutions of $M \_L \geq 4.0$ events in the M_S6.1 Panzhihua-Huili earthquake sequence of $\mathrm{Aug} 30$, $2008[J]$. Chinese Journal of Geophysics, 2010, 53 (12), 2852-2860.

4. Lv Jian, Zeng Wenjing, Xie Zujun, et al. Rupture characteristics of the Ms4.6 Ruichang- Yangxin earthquake of Sep.10, 2011 and the strong earthquake risk in the region. Chinese J. Geophys, (in Chinese), 2012, 55(11), 3625-3633.

5. Yin Xinxin, Chen Jifeng, Liu Jiamin. The Calculation of the FocalDepth of Gansu Province Based on sPn phase[J]. Plateau Earthquake Research, 2013, 25(1):31-34.

6. Chen J, Carpenter N S, Wang Z, et al. Evidence of Complex Faulting near the Huangcheng-Shuangta 
Fault, Gansu, China, from the 11 May 2012 MW 4.8 Sunan Earthquake[J]. Bulletin of the Seismological Society of America, 2016, 106(5):2258-2265.

7. Yin Xinxin, Yang Liming, Chen Jifeng, et al. Study on the One Dimensional Velocity Model in Gansu Area[J]. China Earthquake Engineering Journal, 2017, 39(1).

8. Lv Junqiang, Li Qingmei, Zhao Weidong, et al. Using sPn Phase to Relocate Focal Depths of Felt Earthquakes of Recent Years in Ningxia Area $[\mathrm{J}]$.China Earthquake Engineering Journal, 2016, 38(1):46-50. 